\title{
Multidimensionality of cultural practices: implications for culturally relevant science education
}

\author{
Nancy Ares
}

Received: 28 September 2010/ Accepted: 28 September 2010/Published online: 16 October 2010

(C) Springer Science+Business Media B.V. 2010

\begin{abstract}
Alfred Schademan's close and systematic analysis of the sociohistorical and science-related practices developed by African American men goes a long way in disrupting deficit-based notions of such students' capabilities. The rich resources he identifies open many possibilities for connecting peer and classroom knowledges. This response offers some cautionary notions to consider, given the historical, social and political dimensions that are integral to such practices.
\end{abstract}

Keywords Cultural practices $\cdot$ Spatial theory $\cdot$ Non-dominant youth

In recent years the influence of constructivist thinking has required changes in teachers' stances toward classroom conversations. ... However, we must acknowledge that, even with this more open stance toward science discussions in constructivist classrooms, cultural differences exist. These need not be seen as a detriment to learning but as a resource on which teachers can rely to open up views of scientific meaning and discourse.

(Warren, Ballenger, Ogonowski, Rosebery, and Hudicourt-Barnes 2001)

Alfred Schademan (this volume) grounds his examination of the science-related cognitive and cultural resources African American young men develop through playing the card game, Spades, in the sociocultural milieu in which the game was developed and is now played. For many scholars, such social and cultural practices have dimensions involving content (science in this case), context (Spades play and science classrooms in this case),

Forum response to Schademan, A. (2010). What does playing cards have to do with science? A resource-rich view of African American young men. Cultural Studies of Science Education. DOI 10.1007/s11422-010-9275-5.

N. Ares $(\bowtie)$

Warner School of Education, University of Rochester, Rochester, NY 14627, US

e-mail: nancy.ares@ rochester.edu 
histories, politics (not in the sense of parties or government, but relations of authority and power), and norms for social interaction (Street, Baker and Tomlin 2005). Brian Street's (1984) foundational work in New Literacy Studies argues that literacy learning is not an individual achievement, politically neutral, universal (or the same everywhere), and context- and value-free-what he terms 'autonomous.' Rather, it is context-specific, imbued with power, and a socially constructed achievement—what he terms 'ideological.' Situating literacy learning in larger social and political realms this way pushes us to examine what kinds of practices are legitimated where as we consider bridging contexts (i.e., home, school). Street, Dave Baker and Allison Tomlin's (2005) numeracy studies emphasize and illustrate that numeracy practices also involve content, context, values and social and institutional relations of power. In doing so, Street, Baker and Tomlin argue that school numeracy practices are treated by both schools and families as more legitimate and more 'mathematical' than home numeracy practices, which creates considerable barriers to bridging home and school in substantive ways. My own work (Ares 2010), which is extended here with the aim of building on Schademan's article, examines the political and cultural dimensions of drawing on non-dominant youth's out-of-school practices and provides some cautions as to the potential pitfalls if such work is not done with full understanding of the complexity of historically developed, culturally derived practices.

Moves like Schademan's to recognize the rich resources of non-dominant youth often not acknowledged and sometimes disallowed in science and mathematics classrooms are critically important. His situating them in sociohistorical contexts is also critically important in tying the cognitive to the social and historical (which he did very well). I would like to extend that work to thinking about the implications for drawing on such rich resources in classroom teaching and learning. What I am considering is different from Josianne Hudicourt-Barnes' (2003) important work in science education in some ways. She and the teachers she worked with leveraged bay odans (a form of argumentation common in Haitian Creole communities) as a way to engage Haitian Creole students. They showed marked improvement in participation, demonstrating the rich science learning that ensued when a familiar and powerful form of interaction was allowed and encouraged. Rowhea Elmesky and Gale Seiler (2007) show similar gains in engagement and contribution among African American students when cultural and social values around solidarity, collectivism, and movement expressiveness were treated as valued features of interaction in science classrooms. Both these approaches share commitments to broadening participation and success for marginalized youth through treating culturally, historically derived community practices and values as important resources for learning.

What I am addressing here would move beyond encouragement to use such rich resources to analyzing science-related elements of cultural practices and then working with students explicitly to tie that to knowledge and practices in science. This is similar to the ways that Carol Lee worked in her Cultural Modeling Project (2001) with African American Vernacular English and literary analysis (explored in depth below). The crux of the issue for my paper is thinking through what is involved in drawing on cultural resources that are crossing spaces, heightening attention to both (1) considerations involved in drawing on the resources youth develop in outside-school cultural practicesSpades in this case-in ways that connect them to the practices and learning of science, and (2) the dangers of ignoring cultural, historical and political dimensions of the practices from which those resources develop.

To explore how this crossing of classroom and peer social spaces may be facilitated well and ethically, spatial theory seems a helpful framework. While there are numerous 
variations of spatial theories (see Frink et al. 2009), what I find most helpful here is the notion of spatialized and spatializing practices. As with virtually all spatial theories, this concept is grounded in the view that space is not static, nor something that is filled, but that it has social, political, and historical dimensions (Soja 1996); that it is dynamic and changing rather than static (Buendía and Ares 2006); and that relations of power are embedded, as well as shifting (Foucault 1982).

More specifically:

Spatialized practices are those that are often viewed as 'natural' or appropriate, based on historical, political, social notions; these practices largely reproduce social space (for example, teachers' and students' compliance with desks arranged in rows and the resulting reproduction of traditional teacher/student relations) ... Spatializing practices, on the other hand, are those involved in appropriation and production of space. ... It is this productive quality that entails possibilities for transformation that we see as important for our work aimed at understanding ... practices that involve non-dominant youths' productive creation of social spaces in classrooms and schools. (Ares et al. 2006, p. 12)

What I hope to show here is that to draw on the resources African American young men develop through Spades play, spatializing practices are necessary, as the purpose for engaging in such bridging should be to transform science teaching and learning rather that reproducing classroom practices that, as Elmesky and Seiler (2007) argue, alienate many of these students.

\section{A word about culture}

In social practice views of learning, notions of culture embrace the dynamism and heterogeneity that characterize cultural groups. Following Elmesky and Seiler's (2007) work on communalism among African American students, the focus here is on the performance of Spades play as part of youths' repertoires of practice (Gutierrez and Rogoff 2003) that develop through engagement in practices of their communities. This view of culture avoids simplistic notions that treat cultural groups as homogenous. For example,

By focusing on communalism among African Americans, we are suggesting neither that only African Americans demonstrate this disposition, nor that all African Americans exhibit this disposition to the same degree. To suggest so would be to essentialize culture and to fail to recognize complexity within cultures and subcultures. However, as theorized by William H. Sewell, cultural systems of meanings and associated practices do exist throughout societies, even if only thinly coherent and marked by contradictions. (Elmesky and Seiler 2007, p. 396)

This approach to culture and cultural practices emphasizes attention to both the socially and historically derived aspects of Spades play among African American young men as well as the variety of ways in which individuals may (or may not) engage in such activity.

\section{What might bridging classroom science and Spades play involve?}

In terms of the cognitive aspects of Spades, the important resources identified in terms of, for example, reasoning, predicting, analyzing, and using conditional probabilities (usually 
implicitly) could be approached in a way that follows Lee's (2001) Cultural Modeling Project and Schademan's method of uncovering players' reasoning by recording a game, analyzing the plays, and asking participants to talk through their decisions. In Lee's case, she conducted a close analysis of the literary elements of rap and African American Vernacular English (AAVE) in literature before developing a curriculum that scaffolded students' development of skills and knowledge in literary analysis of canonical texts. Once her analysis was complete, she began her curriculum with rap lyrics and trade books that used AAVE to tell the stories. She and the students analyzed those texts to identify literary features such as irony, satire, types of narrators, and metaphor and then turned to analysis of canonical texts included in the State curriculum.

It's not only cognitive

Not only did Lee draw on resources in texts familiar to students (who were almost exclusively African American), she allowed and invited them to use AAVE and interaction/communication styles often found in African American communities and engaged in by the students with whom she worked. She also used AAVE herself in her teaching, for example, performing the poem, Invictus, in the persona of a Black preacher. The mixture of texts from both in and out of school and of performance and interaction styles seen in Black communities bridged home and school, but also recognized the political, cultural, and literary dimensions of texts, texts produced through engagement in culturally derived practices (in both home and school spaces). In this example, we can see the relation of spatialized and spatializing practices, where the spatialized practices of school and the spatializing practices of Lee and her students created a hybrid space in which the intersection of reproductive and productive activities fostered students' development of important skills in literary analysis that could help them succeed in the institution of school while also recognizing their expertise in community-based, culturally/historically derived practices.

Schademan presents a similarly close analysis of the reasoning and practices involved in Spades play. In his approach to making players' reasoning, the history and development of the game, and other knowledges/practices visible, we can see a beginning of a way to draw on Spades players' rich resources as a precursor to bridging school and peer communities. In terms of cognitive dimensions of Spades, reasoning central science to learning and practice is clear:

Everyday at lunchtime, the Spades players are dealt hands that contain only pieces of a larger picture. Through playing the game, they have developed a number of abilities to help them see past their hands. As a result, they come equipped to our classrooms with the ability to make and memorize observations, draw inferences based upon their observations, and use probabilistic reasoning. ... Like the Spades players, scientists always operate from an incomplete picture of reality. Successful scientists are those who combine their understanding of empirical evidence and use their imagination and creativity to see past the evidence at hand and use it to make inferences about an imagined reality. (Schademan)

In terms of practice-related activities, he shows the ways that collaboration (among teams), creativity (novel plays, reneging), risk-taking (reneging), and communication are key. Additionally, the players' modification of Old School Spades into a new game relied on their adapting the rules and the configuration of cards to serve their purposes of keeping the game interesting and competitive. Science learning in inquiry-based 
classrooms and science in professional practice rely on these practices as well, as teams work on novel and familiar problems, follow leads for ways to approach and solve challenges (risky, as some that could lead to blind alleys or dead ends), and communicate their ideas and findings both among themselves and to others. Further, John Jenkins (1992) notes that science "is about creating new knowledge, or where possible, restructuring, reworking and transforming existing scientific knowledge into forms which serve the purpose in hand. Whatever that purpose (political, social, personal, etc.), it is essentially concerned with action or capability, rather than with the acquisition of knowledge for its own sake" (p. 236). Thus, as Schademan notes, the richness of the game's content and practice means there are multiple resources to draw upon to bridge peer and science classroom practices.

It's more than a game

Obviously, though, simply having a Spades tournament in class is not the way to proceed. Writing about science curriculum development with indigenous peoples in Alaska, Sidney Stephens (2001) asserts that, "culturally responsive curricula...devotes substantial blocks of time and provides ample opportunity for students to develop a deeper understanding of culturally significant knowledge linked to science. It incorporates teaching practices that are both compatible with the cultural context, and focus on student understanding and use of knowledge and skills" (p. 7). Given the need to focus on making explicit connections to science learning and on rigorous academic learning, Spades play in the classroom must become not just a game-playing activity but an opportunity to explore important cultural and social resources with students in service of science learning and deep engagement. Further, ignoring the cultural and historical value attached to the game could be insulting and alienating for many African American youth and communities. It would also deny students (and not just African Americans) a chance to learn about that history and to connect it to science learning and practice, enriching the curriculum.

Seth Agbo (2001) goes still further in tying curriculum development with Native American communities to cultural identity work. Not only is the history and content of indigenous knowledge the focus of attention, what Gloria Ladson-Billings (1997) calls cultural competence (skill and expertise in knowledge and practices central to one's community) and resistance to deficit views of non-dominant youth and communities are also at the core:

The premise of our project was, therefore, to examine how the powerful communal bonds of aboriginal identities, shaped by communal language, ethnicity, and culture affect knowledge and learning rather than educational standards imposed by the European-American system and status identities created by class or profession. In contrast to the stupendous and complex educational content that reduces the Mohawk student to conditions of abstraction and anonymity, we embarked on a cultural model viewed as the repository of cherished knowledge that places culture as the nexus in the education of the Mohawk child. (p. 33)

This is a more encompassing view of bridging school and community than identifying science content in everyday life when everyday life or cultural practices are seen in narrow ways that ignore their multidimensionality. For Spades play, recognition that youth and community identities are involved and making explicit that the game's role in cultural competence and healthy cultural identification is acknowledged would be critical. 
Spades as performance

However, energetic performance, emphatic gesture, trash talking, dominance, intimidation, etc. are central to the context and play of the game. This is also something to consider in drawing on the resources constructed through playing the game. The importance of performance, and particular kinds of performance, to the play of the game has historical and cultural roots and so its value cannot be underestimated. On the one hand, dampening or sanitizing game play to be more sedate and aligned with conventional classroom decorum could strip the game of important dimensions, while on the other hand, it could alienate students who play and whose families and communities play not only as a pleasurable pursuit, but as a form of cultural identification (see Ares 2010). This is another aspect for which Seiler and Elmesky's (2007) work is important to consider:

at City High in Philadelphia... [in] hallways and classrooms it is common to hear students rapping and singing and to see them breaking into a few dance steps or swaying as they walk. Energy is high, synchronous movement is prevalent, and rhythm seems to be present within individuals and visible in their interactions with others. However, ... Despite the respect, admiration, and reinforcement that youth may receive from their peers, teachers and administrators ...frequently view African American students' forms of expression such as movement, singing, rapping, and beating as detrimental to the generation of a productive learning environment and, particularly in science classes, teachers consider them to be outside the norm. (Elmesky and Seiler 2007, p. 74)

So, together with content and history, performance styles that challenge conventional classroom norms would be critical to address or allow to capture the multidimensionality of the game and the possibilities for transforming science learning and teachingspatializing the classroom to be productive of hybrid forms of practice rather than reproductive of practices that marginalize many African American youth.

Finally, the political dimensions of Spades play in relation to classroom and school, as well as the discipline of science, are critical to address. Elizabeth Fine (2003) examines the institutionalization of Stepping, a form of dance important in African American communities, particularly sororities and fraternities, that involves groups' precisely coordinated, intricate arm and leg movements, loud stomping/marching, chants, and music. Its beginnings have been traced to the South during slavery, where it served as a link to African tribal dance and a means of retaining cultural practices in the face of oppression. Fine's exploration of what gets lost when Stepping is institutionalized in formal Step shows is germane. In particular, cracking, a regular feature of less formal Step competitions in which teams tease or mimic each other in derogatory ways, was disallowed in the formal settings because of the tensions it adds to the performances. Fine also writes about worries around the commodification of Step:

In the process of teaching stepping to children, Step Afrika! USA have had to examine what parts of their Greek stepping tradition are appropriate to share with non-Greeks ... Some of what we do is considered sacred... Like other popular African American cultural expressions such as slang, rap, and the blues, stepping may become widely commercialized and adopted by non-African Americans. "If it becomes too commercialized," says Brookins, "African Americans will move away from it $\ldots$ or we will change it to such an extent that it's not recognizable in its 
original art form. You'll be able to see the roots in it, but it will transcend. Just like with our slang, when other cultures pick it up, we drop it." (2003, pp. 145, 146)

Clearly, care in considering whether and how to draw on social and cultural resources requires that we examine practices like Spades play—and Step dance—as value-laden and as bound to sociohistorical and sociopolitical contexts.

\section{Hybrid social spaces}

Spatializing practices in the case of Spades play in science classrooms would allow for transformation of norms for classroom interaction and language use, as well as sources of curriculum. Such practices would embrace (1) the historical dimensions of the game as a culturally valued African American pursuit, (2) the social interaction dimensions of classrooms as social spaces where expertise in performance of a uniquely African American style of play is recognized, (3) the content dimensions of classrooms as social spaces where scientific reasoning and knowledge developed in Spades play are used as a resource for rigorous science learning, and (4) the political dimensions where authority and exercises of power in the classroom are shared among teachers and students, given student expertise in the game that it is a part of African American history and present-day practice, and teacher expertise in science. Hybridity would then, as in Lee's case of Cultural Modeling, result from teachers and students tying in science content and standards, a spatialized practice grounded in school science that has its own purposes and goals for student learning, many of which are legitimate in supporting youths' development of rigorous learning and some of which engage students in the "language of power" (Delpit 1992). For example, this hybrid space would need to include attention to standardized testing: "Whether or not scholars can agree on the significance of standardized tests, their meaning in the real world serves to rank and categorize both schools and individuals. Thus, teachers... are compelled to demonstrate that their students achieve... No matter how good a fit develops between home and school culture, students must achieve”. Spatialized and spatializing practices together could produce an inviting, invigorating, productive, and engaging science classroom space.

\section{Conclusion}

This kind of work to recognize that games, as well as indigenous knowledges and other 'out-of-school' activities, involve more than practices and knowledge that can be imported into school leads us to consider cultural and social histories, values and beliefs, but also the politics of schooling. Agbo's work with Mohawk communities that centers indigenous culture in curriculum and student learning, Elmesky and Seiler's work that seeks to open the space of schools and classrooms to welcome African American values of communalism and expressive movement, and Schademan's work that challenges schools' and society's deficit notions of African American young men do not only offer evidence and examples of ways that cultural practices of non-dominant communities and youth can be powerful resources for learning. They also challenge notions of the purpose of school science (and schooling more broadly). Rather than being a homogenizing process focused on standardizing not only curriculum but youth, schooling could be transformed to be a space where cultural diversity is viewed in a profound sense that includes attention to youth as cultural beings whose identities, achievements, learning and development are tied to the 
kinds of invitations schools offer them to engage, succeed and grow. Those invitations could, as Schademan shows, encourage youth to bring to bear and teachers to draw on the multidimensionality that out-of-school practices, such as Spades play, embody.

\section{References}

Agbo, S. A. (2001). Enhancing success in American Indian students: Participatory research at Akwesasne as part of the development of a culturally relevant curriculum. Journal of American Indian Education, $40(1), 31-56$.

Ares, N. (2010). Political and cultural dimensions of organizing learning around funds of knowledge. In W. R. Penuel and K. O'Connor (Eds.), Learning research as a human science: National Society for the Study of Education Yearbook, 109(1), 192-206.

Ares, N., Evans, D. M., \& Schademan, A. (2006). Mathematics and numeracy as social and spatial practice. Paper presented at the American Educational Research Association meeting, San Francisco, CA.

Buendía, E., \& Ares, N. (2006). Geographies of difference: Constructing Eastside, Westside and Central City students and schools. Geographies and communication, New York: Peter Lang.

Delpit, L. D. (1992). Acquisition of literate discourse: Bowing before the master? Theory into Practice, 31, 296-302.

Elmesky, R., \& Seiler, G. (2007). Movement expressiveness, solidarity and the (re)shaping of African American students' scientific identities. Cultural Studies in Science Education, 2, 73-103.

Fine, E. C. (2003). Soul stepping: African American step shows. Chicago: University of Illinois Press.

Foucault, M. (1982). The subject and power. In H. L. Dreyfus \& P. Rabinow (Eds.), Michel Foucault: Beyond structuralism and hermeneutics (2nd ed.). Chicago, IL: University of Chicago Press.

Frink, J., Ares, N., Mudkopadhyay, M., \& Tsoumani, E. (2009). Hybridity and transformation: Social spaces and youth cultural practices. In N. Ares (Ed.), Youthful productions: Cultural practices and constructions of content and social spaces (pp. 65-96). New York: Peter Lang.

Gutierrez, K., \& Rogoff, R. (2003). Cultural ways of knowing: Individual traits or repertoires of practice? Educational Researcher, 32(5), 19-25.

Hudicourt-Barnes, J. (2003). The use of argumentation in Haitian Creole science classroom. Harvard Educational Review, 73(1), 73-93.

Jenkins, E. W. (1992). School science education: Towards a reconstruction. Journal of Curriculum Studies, 24, 229-246.

Ladson-Billings, G. (1997). Toward a theory of culturally relevant pedagogy. American Education Research Journal, 32, 465-491.

Lee, C. D. (2001). Is October Brown Chinese? A cultural modeling activity system for underachieving students. American Educational Research Journal, 38, 97-141.

Liggett, H., \& Perry, D. C. (1995). Spatial practices. London: Sage.

Seiler, G., \& Elmesky, R. (2007). The role of communal practices in the generation of capital and emotional energy among urban African American students in science classrooms. Teachers College Record, 109, 391-419.

Soja, E. (1996). The trialectics of spatiality. In E. Soja (Ed.), Thirdspace: Journeys to Los Angeles and other real-and-imagined places (pp. 54-82). Cambridge, MA: Blackwell.

Stephens, S. (2001). Handbook of culturally responsive science curriculum. Fairbanks, AL: Alaska Native Knowledge Network, Alaska University.

Street, B. V. (1984). Literacy in theory and practice. Cambridge: Cambridge University Press.

Street, B. V., Baker, D. A., \& Tomlin, A. (2005). Navigating numeracies: Home/school numeracy practices. London: Kluwer.

\section{Author Biography}

Nancy Ares is an associate professor in Teaching \& Curriculum at the University of Rochester. Her research focuses on cultural practices, language, relations of power, and participation in classrooms and communities. Critical sociocultural and spatial theories guide her work that views non-dominant youth and communities as rich in resources that should be central to learning and development. 